\title{
Self-reported awareness and attitude of cancer patients towards clinical nurse coordinators
}

\author{
Ahmad Deeb ${ }^{1}$, Mohammad O. AlKaiyat ${ }^{2}$, Emad Abu Hlal ${ }^{3}$, Areej Attari ${ }^{3}$, Rania Mahaireh ${ }^{3}$, Mohammad R. \\ Alqudimat ${ }^{4}$, Mahmoud Salam *1 \\ ${ }^{1}$ King Abdullah International Medical Research Center, King Saud University for Health Sciences, Riyadh, Saudi Arabia \\ ${ }^{2}$ Department of Oncology, Ministry of National Guard Health Affairs, Riyadh, Saudi Arabia \\ ${ }^{3}$ King Hussein Cancer Center, Amman, Jordan \\ ${ }^{4}$ Sultan Bin Abdulaziz Humanitarian City, Riyadh, Saudi Arabia
}

Received: January 10, 2017

DOI: $10.5430 /$ jnep.v7n7p95
Accepted: February 12, $2017 \quad$ Online Published: February 22, 2017

URL: https://doi.org/10.5430/jnep.v7n7p95

\begin{abstract}
Background and objective: Lack of knowledge or poor perception towards the roles and responsibilities of clinical nurse coordinators among cancer patients might lead to a decrease in seeking their services. The objective of the study was to assess the knowledge, perception and attitude towards clinical nurse coordinators among cancer patients at a specialized cancer center in Jordan.
\end{abstract}

Methods: This is a cross sectional study that was conducted by distributing a self-reported and anonymous survey to 240 cancer patients visiting the center. The survey questioned some patient characteristics such as sex, age, educational level, marital status, disease type and duration, type of therapy. The patients' knowledge (12-statement), the perception (9-statement) regarding the actual roles/responsibilities of coordinators and the attitude (5-statement) towards seeking their services were measured. Responses on Likert scales were converted to percentage mean scores.

Results: The overall percentage mean scores \pm standard deviation of knowledge was $59 \pm 17$, perception towards clinical nurse coordinators $(79 \pm 14)$ and attitude towards seeking their services $(69 \pm 16)$. Linear regression showed that participants on chemotherapy had significantly better perception (higher scores) compared to participants on concurrent therapies $(\beta=-3.91, p=$ .049). Participants with higher knowledge scores had better perception indicating a better comprehension about the clinical nurse coordinators' roles, compared to those with lower knowledge percentage mean scores $(\beta=0.13, p=.019)$. Female patients had higher percentage mean score of attitude compared to male particpants $(\beta=-3.77, p=.034)$. Better perception of Clinical nurse coordinators (CNCs) among cancer patients was significantly more associated with a more positive attitude towards seeking CNC services $(\beta=0.72, p<.001)$.

Conclusions: Patients' knowledge about the roles and responsibilities of nurse coordinators is associated with a better patients' perception towards coordinators, which in return is associated with a more positive attitude towards seeking their services. Special consideration should be paid for patients on concurrent therapies who were more likely to have poorer perception towards clinical care coordinators compared to patients on chemotherapy. In addition, coordinators are expected to observe a more negative attitude towards seeking their services among male cancer patients.

Key Words: Knowledge, Perception, Attitude, Clinical nurse coordinator, Cancer patients

*Correspondence: Mahmoud Salam; Email: mahmoudsalam@ @otmail.com; Address: Science and Technology Unit, King Abdullah International Medical Research Center, King Saud University for Health Sciences, Riyadh, Saudi Arabia.

Published by Sciedu Press 


\section{INTRODUCTION}

An advanced practice nurse (APN) is a great asset for any healthcare institution that visualizes itself as a provider of a safe and high quality nursing care. Advanced practice nurses could be nurse practitioners, clinical nurse specialists, nurse midwives, nurse anesthetists, or others who are basically registered nurses with extensive clinical experience, a post graduate degree, and/or a licensure to practice. ${ }^{[1-3]} \mathrm{A}$ clinical nurse coordinator (CNC) is an APN often referred to among the nursing communities as a case manager or a patient navigator, who reports to the nursing services. ${ }^{[4]}$

Clinical nurse coordinators especially in cancer centers carry an immense responsibility towards a complex patient population that experience stressful and unpredictable health conditions. ${ }^{[5]}$ Cancer patients and their families often report fear, anxiety, and confusion ${ }^{[6]}$ as treatment requires a wide array of modalities such as chemotherapy, radiotherapy, surgery and hormonal therapy. ${ }^{[7]}$ Cancer patients require close observation and regular follow-ups, as well as supportive care and rehabilitation throughout the treatment period up till its completion. ${ }^{[7]}$ Being diagnosed with cancer is usually stressful for both patients and their families which might compromise their level of concentration to comply with treatment modalities. These modalities might be diverse and time dependent following a preset or a defined sequence. ${ }^{[7]}$ It has been reported that continuous education for cancer patients aids in psychosocial support and in raising their awareness of the disease, treatment plan, complications, and medication side effects/toxicities. ${ }^{[5]}$

The CNC represents the liaison between patients and families from one side and various health services from the other side. ${ }^{[8]}$ Bridging the gap between the cancer patient and various health disciplines is the ultimate goal for any CNC. Physicians, nurses and other health specialists might be driven unintentionally to a service-focused approach, or simply overwhelmed with their clinical responsibilities due to time constraints or heavy workload. ${ }^{[9]}$ Therefore, a CNC helps in orchestrating all these multidisciplinary health services, coordinating their efforts, following up on them, ensuring they are delivered on time, and observing compliance. In other words, $\mathrm{CNC}$ role is essential in establishing a true patient-centered care approach. ${ }^{[10]}$

The CNCs' primary role is to meet and orient all cancer patients to the health care system from day one. Clinical nurse coordinators are competent in their responsibilities from conducting physical assessment, to referrals, evaluation, coordination, education and follow-ups. Nurse coordinators collaborate with other health care providers to facilitate a multidisciplinary patient-centered care service. They are actively involved in quality improvement projects of patient care and safety, developing policies, clinical guidelines, and procedures. These coordinators are responsible to educate patients and their families about their rights and responsibilities, medical conditions, diagnostic tests, treatment options, potential side effects, prognosis, health promotion, nutritional information, and so on. A lack of knowledge or poor perception towards the roles and responsibilities of CNCs among cancer patients might lead to a decrease in seeking their services. Patients often miss on a great opportunity to receive a well-coordinated, high quality and safe health care services by simply not communicating or referring to CNCs. Literature mainly highlighted the perception of patients towards the quality of nursing care, nursing behavior, and other nursing roles..$^{[9,11,12]}$

This study aimed to assess the awareness and attitude towards CNCs among cancer patients at the out-patient clinics of a cancer center in Jordan, Middle East. This was achieved by: 1) describing some patients' characteristics, 2) assessing patients' knowledge, perception, and attitude towards the services provided by $\mathrm{CNCs}$, and 3 ) determining their associated factors.

\section{METHODS}

\subsection{Study design}

Cross sectional descriptive study.

\subsection{Study setting}

Inaugurated in 1997, King Hussein Cancer Center (KHCC) is one of the leading cancer specialized hospitals in the Middle East. KHCC accommodates over 3,500 new cancer patients each year. This 170-bed institution employs a team of highlyqualified healthcare professionals comprised of almost 200 oncologists/consultants and 617 nurses. This center provides comprehensive cancer care from primary care, through diagnosis and treatment, to palliative care. It has been accredited by the Joint Commission International since 2006. Cancer patients visit 14 outpatient specialty clinics for consultation, procedure or treatment, and leave on the same day. A range of 150-200 patients visit these clinics daily, the latter are attended to by 16 CNCs. All KHCC outpatient visitors are attained for upon their first registration in the clinics and throughout their treatment. The service provided by CNCs is part of the routine care provided by the cancer center. One CNC is allocated for each of the 14 cancer specialty clinics, with each CNC providing services to a range of 15 to 30 patients daily. 


\subsection{Study subjects and sampling technique}

By convenience, adult patients who were medically registered at the KHCC outpatient clinics were invited to enroll in this study between April and June 2010. Eligible participants were those who have met and communicated to CNCs during their visits. Conscious, oriented and medically stable study participants were recruited during their presence in the waiting area with no interruptions to the clinical services delivered to them. Newly registered patients (less than 1 month) were excluded. Based on the assumption that a percentage mean score (PMS) $>60 \%$ (above the Likert score 2.5) denotes favorable awareness and attitude among KHCC visitors, and with a margin of error of $6 \%$, and $95 \%$ confidence limits, the sample size was estimated to be 256 .

\subsection{Data collection}

The data collection team constituted of four nurses working at KHCC, Jordan. The principle investigator was involved in the training and supervision of this team on how to identify and recruit eligible participants at the setting, provide them with the questionnaire, and gather their response.

The knowledge domain was constructed based on the roles and responsibilities enlisted in the KHCC job description of the CNC. This job description was created in 2003 based on the Strong Model of Advanced Practice Nursing, from which the survey questioned particpants in regards to some of its components such their comprehensive care, education, importance of role and qualifications. ${ }^{[8]}$ No specific tools were found to assess the awareness and attitude of cancer patients to CNCs. Therefore, the perception and attitude domains were derived and customized from validated tools previously utilized by published studies to measure the patients' perception toward general nursing care, quality of nursing care, nursing care behavior, and other nursing roles. ${ }^{[9,11,13,14]}$

The data collection forms consisted of:

- Invitation letter: This part presented the general aim of this study and provided the contact details of the principal investigator, in case any query was raised.

- Participant characteristics: This section inquired on a number of aspects such as sex, age, educational level, marital status, cancer type, duration of disease and type of treatment.

- Outcome characteristics: Awareness (Knowledge and perception) and Attitude.

The knowledge domain comprised of 12 questions, where the feedback of participants was evaluated as true (score $=1)$ and false or don't know (score $=0$ ) for each question. The 1st, 5th, 8th, 9th, 10th, and 11th knowledge questions were accounted as false statements, while the others were accounted as true statements. Participants who responded to the 12th question " $\mathrm{CNC}$ is both a registered nurse and advanced practice nurse" were accounted as correct (see Table 1). The total score of the knowledge questions was converted to PMS. The perception of participants towards the services provided by CNCs was assessed by 9 positively directed statements (see Table 2). Five attitudinal statements (all positive direction) were responded to by study participants (see Table 3). The responses to perception and attitude statements on the fivepoint Likert scale were converted to scores (strongly disagree $=0$, disagree $=1$, neutral $=2$, agree $=3$, and strongly agree $=4$ ) and their PMS were commuted.

A number of reliability and validity tests were applied to the customized data collection tool that was derived from previous studies. ${ }^{[9,11,13,14]}$ The tool was translated to the locally predominant Arabic language in the community and then translated back to English language, with minimal variations observed. The statements were evaluated by a panel of five experts in social science studies. The data collection forms were revised by a local editorial service that customized it with locally familiar terms and edited it accordingly. A pilot test was conducted on a group of 20 patients. Complex scientific terms were simplified. Internal consistency and face validity were done. Cronbach's alpha was 0.68 .

\subsection{Data analysis}

Data analysis was conducted using the Statistical Package for the Social Sciences (Version 23; SPSS Inc., Chicago, IL, USA). Categorical data were illustrated in frequencies and percentages. Normality tests using the skewness coefficient indicated that knowledge was normally distributed, while perception and attitude were both not normally distributed. The arithmetic mean and standard deviation were used as a summary of statistics for all domains. Student's $t$-test and one-way analysis of variance (ANOVA) were used as a test of significance to compare the PMS of knowledge, while Mann Whitney and Kruskal-Wallis tests were used as a test of significance to compare the PMS of perception and attitude. Linear regression analysis was used to determine the significant factors associated with higher perception and attitude scores towards the services provide by CNCs. A $p$-value of $<.05$ was considered to be statistically significant.

\subsection{Ethical considerations}

The questionnaire was carried out among study participants after offering them a cover letter and after clarifying the aim of the study. Patients were reminded that their particpation were voluntary and confidential, and assured that their feedback won't affect the quality of health care services provided at the clinics. Study participants agreed by signing on the the 
consent. Since the questionnaire was self-administered and created during data collection. This study was approved by kept in sealed envelopes, no stressors or influential bias was the Institutional Review Board of the KHCC, Jordan.

Table 1. Frequency and percentage distribution of patients' response to knowledge statements $(n=240)$

\begin{tabular}{|c|c|c|c|}
\hline \multirow[b]{2}{*}{ Knowledge } & \multicolumn{3}{|l|}{ Responses } \\
\hline & $\begin{array}{l}\text { Yes } \\
\text { n (\%) }\end{array}$ & $\begin{array}{l}\text { No } \\
\text { n (\%) }\end{array}$ & $\begin{array}{l}\text { Don't know } \\
\text { n (\%) }\end{array}$ \\
\hline 1) The clinical nurse coordinator prescribes medications to patients. & $54(22.5)$ & $147(61.2)$ & $39(16.3)$ \\
\hline 2) The clinical nurse coordinator conducts preliminary health assessment during the patient's first visit. & 196(81.7) & 26(10.8) & 18(7.5) \\
\hline $\begin{array}{l}\text { 3) The clinical nurse coordinator provides health education and medical information for patients based } \\
\text { on their condition. }\end{array}$ & 198(82.5) & 23(9.6) & 19(7.9) \\
\hline 4) The clinical nurse coordinator follows up on the diagnostic tests of patients. & 182(75.8) & $31(12.9)$ & 27(11.3) \\
\hline 5) The clinical nurse coordinator participates in the surgical procedures inside operating rooms. & $57(23.8)$ & 101(42.0) & $82(34.2)$ \\
\hline 6) The clinical nurse coordinator schedules the clinic appointments and visit dates for the patients. & 219(91.3) & $9(3.7)$ & $12(5.0)$ \\
\hline $\begin{array}{l}\text { 7) The clinical nurse coordinator coordinates the therapeutic plan for the patient (operations, } \\
\text { admission/discharge, diagnostic tests, chemotherapy, etc.). }\end{array}$ & $156(65.0)$ & $49(20.4)$ & $35(14.6)$ \\
\hline 8) The clinical nurse coordinator requests laboratory tests as needed. & $160(66.7)$ & $49(20.4)$ & $31(12.9)$ \\
\hline 9) The clinical nurse coordinator administers chemotherapy. & $57(23.8)$ & 131(54.5) & $52(21.7)$ \\
\hline 10) The clinical nurse coordinator requests diagnostic tests. & 131(54.6) & $66(27.5)$ & 43(17.9) \\
\hline 11) The clinical nurse coordinator documents the medical reports. & $117(48.8)$ & $73(30.4)$ & $50(20.8)$ \\
\hline \multicolumn{4}{|l|}{ 12) The clinical nurse coordinator is a: } \\
\hline -Secretary & $8(3.3)$ & & \\
\hline -Nurse technician & $35(14.6)$ & & \\
\hline -Registered nurse & $50(20.8)$ & & \\
\hline -Advanced practice nurse & 137(57.1) & & \\
\hline -Physician & $10(4.2)$ & & \\
\hline
\end{tabular}

Note. n: Frequency, \%: percentage.

Table 2. Frequency and percentage distribution of patients' response to perception statements $(n=240)$

\begin{tabular}{|c|c|c|c|c|c|}
\hline \multirow[b]{2}{*}{ Perception } & \multicolumn{5}{|l|}{ Responses } \\
\hline & $\begin{array}{l}\text { Strongly } \\
\text { agree } \\
\text { n (\%) }\end{array}$ & $\begin{array}{l}\text { Agree } \\
\text { n (\%) }\end{array}$ & $\begin{array}{l}\text { Neutral } \\
\text { n (\%) }\end{array}$ & $\begin{array}{l}\text { Disagree } \\
\text { n (\%) }\end{array}$ & $\begin{array}{l}\text { Strongly } \\
\text { Disagree } \\
\text { n (\%) }\end{array}$ \\
\hline $\begin{array}{l}\text { 1) I believe the clinical nurse coordinator is a key health provider in } \\
\text { outpatient clinics. }\end{array}$ & $106(44.2)$ & $97(40.4)$ & $30(12.5)$ & $4(1.7)$ & $3(1.3)$ \\
\hline $\begin{array}{l}\text { 2) I believe the clinical nurse coordinator is a link between the } \\
\text { patient and other health disciplines. }\end{array}$ & 101(42.1) & $114(47.5)$ & $14(5.8)$ & $9(3.8)$ & 2(8) \\
\hline $\begin{array}{l}\text { 3) I believe the clinical nurse coordinator is qualified by education } \\
\text { to deal with my medical condition. }\end{array}$ & $99(41.3)$ & 101(42.1) & $26(10.8)$ & $11(4.6)$ & $3(1.3)$ \\
\hline $\begin{array}{l}\text { 4) I believe the clinical nurse coordinator is specialized by work } \\
\text { experience to deal with my medical condition. }\end{array}$ & $49(20.4)$ & 73(30.4) & $57(23.8)$ & $50(20.8)$ & $11(4.6)$ \\
\hline $\begin{array}{l}\text { 5) I believe the coordinator follows up on my disease prognosis, } \\
\text { diagnostic tests and medical condition. }\end{array}$ & $85(35.4)$ & $108(45.0)$ & 28(11.7) & $12(5.0)$ & $7(2.9)$ \\
\hline $\begin{array}{l}\text { 6) I believe the clinical nurse coordinator preserves the } \\
\text { confidentiality of my health-related information. }\end{array}$ & $120(50.0)$ & $96(40.0)$ & 23(9.6) & $0(0)$ & $1(0.4)$ \\
\hline $\begin{array}{l}\text { 7) I believe the clinical nurse coordinator's role improves on the } \\
\text { quality of health care services. }\end{array}$ & 133(55.4) & $92(38.3)$ & $12(5.0)$ & $2(0.8)$ & $1(0.4)$ \\
\hline $\begin{array}{l}\text { 8) I believe the clinical nurse coordinator follows up properly on } \\
\text { my treatment and compliance. }\end{array}$ & 79(32.9) & $116(48.3)$ & 28(11.7) & $15(6.3)$ & $2(0.8)$ \\
\hline $\begin{array}{l}\text { 9) I believe the clinical nurse coordinator will respond to me if I } \\
\text { have a question or concern. }\end{array}$ & 103(42.9) & $106(44.2)$ & 20(8.3) & $10(4.2)$ & $1(0.4)$ \\
\hline
\end{tabular}

Note. n: Frequency, \%: percentage. 
Table 3. Frequency and percentage distribution of patients' response to attitude statements $(n=240)$

\begin{tabular}{llllll}
\hline & \multicolumn{2}{l}{ Responses } & & & \\
\cline { 2 - 6 } Attitude & $\begin{array}{l}\text { Strongly } \\
\text { agree } \\
\mathbf{n}(\%)\end{array}$ & $\begin{array}{l}\text { Agree } \\
\mathbf{n}(\%)\end{array}$ & $\begin{array}{l}\text { Neutral } \\
\mathbf{n}(\%)\end{array}$ & $\begin{array}{l}\text { Disagree } \\
\mathbf{n}(\%)\end{array}$ & $\begin{array}{l}\text { Strongly } \\
\text { Disagree } \\
\mathbf{n}(\%)\end{array}$ \\
\hline $\begin{array}{l}\text { 1) I will refer to my clinical nurse coordinator in case I had an } \\
\text { emergency. }\end{array}$ & $111(46.3)$ & $98(40.8)$ & $17(7.1)$ & $10(4.2)$ & $4(1.7)$ \\
$\begin{array}{l}\text { 2) I will refer to a medical consultant rather than a clinical } \\
\text { nurse coordinator if available. }\end{array}$ & $45(18.8)$ & $55(22.9)$ & $33(13.8)$ & $82(34.1)$ & 25(10.4) \\
$\begin{array}{l}\text { 3) I will consult with the clinical nurse coordinator if I have a } \\
\text { question related to my medical condition. }\end{array}$ & $99(41.3)$ & $91(37.9)$ & $26(10.8)$ & $18(7.5)$ & $6(2.5)$ \\
$\begin{array}{l}\text { 4) I will refer to my coordinator if my medical condition is } \\
\text { affecting my psychological/social welfare. }\end{array}$ & $43(17.9)$ & $73(30.4)$ & $56(23.3)$ & $58(24.2)$ & $10(4.2)$ \\
$\begin{array}{l}\text { 5) I will refer to the clinical nurse coordinator to guide me to } \\
\text { various hospital services if I needed them. }\end{array}$ & $83(34.6)$ & $127(52.9)$ & $18(7.5)$ & $11(4.6)$ & $1(0.4)$ \\
\hline
\end{tabular}

Note. n: Frequency, \%: percentage.

\section{RESULTS}

\subsection{Sample characteristics}

A total of 240/247 (97\%) eligible study participants were enrolled in this study. All of the participants were Jordanians, most of which were females (71\%). Almost half (48\%) were above 50 years of age, $36 \%$ between $35-50$ years old, and $16 \%$ less than 35 years old. Participants with university level education were $53 \%$, while $47 \%$ had a school level education. Around $83 \%$ of the study participants were married and $17 \%$ were either single or separated. The leading cancer diagnosis was breast cancer (45\%), colon/gastric cancers (15\%), lymphomas $(11 \%)$, lung cancer $(8 \%)$, prostate/testicular cancer $(5 \%)$ and others $(16 \%)$. Half of participants had disease duration of $<1$ year, while $22 \%$ endured the disease for 3 years and above. Participants on chemotherapy were $35 \%$ and $65 \%$ were on combined therapy (see Table 4).

\subsection{Awareness and attitude of study participants}

The percentage mean score of knowledge on the actual roles and responsibilities of clinical nurse coordinators was 59.2 \pm 16.9 . Some study subjects had wrong responses when asked if CNCs are licensed to prescribe medications (38.8\%) or if they are eligible to administer chemotherapeutic agents $(45.5 \%)$. The majority of participants reported correct responses about the role of CNSs to conduct preliminary health assessment (82\%) and to provide health education /medical information for cancer patients $(83 \%)$. Other knowledge findings are listed in Table 1. The overall PMS of perception towards CNCs was $78.7 \pm 14.1$. Almost $85 \%$ of participants believed that the CNC is a key health provider in outpatient clinic, and $90 \%$ believed that the $\mathrm{CNC}$ is the link between the patient and other health disciplines. Responses to perception statements are presented in Table 2. The overall PMS of participants' attitude towards seeking their services was 68.9 \pm 15.8 . Around $87 \%$ agreed that they would refer to the $\mathrm{CNC}$ in case they had an emergency, $48 \%$ of participants would refer to CNC for help if their medical condition is affecting their psychological or social welfare, and $88 \%$ of participants would refer to the $\mathrm{CNC}$ to guide them to various hospital services upon need (see Table 3).

\subsection{Associated factors with better awareness and atti- tude}

Bivariate analysis initially revealed that participants on concurrent cancer therapy modalities $(60.9 \pm 17.7)$ had higher knowledge scores compared to participants on chemotherapy $(56.1 \pm 15.0), p=.035$. Lung cancer participants had the highest perception PMS $(86.3 \pm 8.9)$ compared to the other groups ( $p=.005$ ), while the lymphoma participants had the highest attitude PMS $(74.5 \pm 12.3)$ compared to the other groups $(p=.004)$. Female participants $(70.6 \pm 14.4)$ also showed better attitude towards seeking the services of CNCs compared to the male participants $(64.7 \pm 18.1, p=.027)$.

Nevertheless, variables were adjusted for and all possible confounders were controlled in two linear regression models, participants on chemotherapy had significantly better perception to CNCs compared to participants on concurrent therapy $(\beta=-3.91, p=.049)$. Participants with better knowledge regarding the roles and responsibilities of CNCs had better perception compared to those with less knowledge ( $\beta=0.13$, $p=.019)$. Higher attitudinal scores were associated with female participants compared to male participants $(\beta=-3.77$, $p=.034)$. Participants with higher perception scores were significantly more likely to report higher attitudinal scores towards seeking the services of CNCs $(\beta=.72, p<.001)$ (see Table 5). 
Table 4. Sample characteristics compared by the percentage mean scores of knowledge, perception and attitude $(\mathrm{n}=240)$

\begin{tabular}{|c|c|c|c|c|}
\hline & $\begin{array}{l}\text { n (\%) } \\
240(100)\end{array}$ & $\begin{array}{l}\text { Knowledge } \\
\text { \% mean score } \\
\bar{X} \pm \text { SD } \\
59.2 \pm 16.9\end{array}$ & $\begin{array}{l}\text { Perception } \\
\% \text { mean score } \\
\bar{X} \pm \text { SD } \\
78.7 \pm 14.1\end{array}$ & $\begin{array}{l}\text { Attitude } \\
\% \text { mean score } \\
\bar{X} \pm \text { SD } \\
68.9 \pm 15.8\end{array}$ \\
\hline \multicolumn{5}{|l|}{ Sex } \\
\hline Male & $69(28.8)$ & $58.7 \pm 17.0$ & $77.1 \pm 17.4$ & $64.7 \pm 18.1$ \\
\hline \multirow[t]{2}{*}{ Female } & $171(71.2)$ & $59.4 \pm 17.0$ & $79.3 \pm 12.6$ & $70.6 \pm 14.4$ \\
\hline & & $t=-0.293, p=.770$ & $\mathrm{z}=-0.588, p=.557$ & $\mathrm{z}=-2.205, p=.027^{*}$ \\
\hline \multicolumn{5}{|l|}{ Age category } \\
\hline$<35$ & $37(15.4)$ & $59.5 \pm 15.9$ & $78.2 \pm 11.2$ & $70.4 \pm 11.8$ \\
\hline $35-50$ & $87(36.3)$ & $60.2 \pm 17.4$ & $78.6 \pm 15.9$ & $70.7 \pm 15.9$ \\
\hline \multirow[t]{2}{*}{$>50$} & $116(48.3)$ & $58.4 \pm 17.0$ & $78.9 \pm 13.7$ & $67.2 \pm 16.7$ \\
\hline & & $\mathrm{F}=0.26, \mathrm{df}=2, p=.766$ & $\chi_{\mathrm{KWT}}^{2}=0.88, \mathrm{df}=2, p=.644$ & $\chi_{\mathrm{KWT}}^{2}=3.368, \mathrm{df}=2, p=.186$ \\
\hline \multicolumn{5}{|l|}{ Education } \\
\hline School level & $113(47.1)$ & $58.3 \pm 17.4$ & $78.9 \pm 11.7$ & $69.6 \pm 15.6$ \\
\hline \multirow[t]{2}{*}{ University level } & $127(52.9)$ & $59.9 \pm 16.6$ & $78.5 \pm 16.0$ & $68.4 \pm 16.0$ \\
\hline & & $t=-0.74, p=.456$ & $\mathrm{z}=-0.563, p=.573$ & $z=-0.491, p=.624$ \\
\hline \multicolumn{5}{|l|}{ Marital status } \\
\hline Single & $24(10.0)$ & $57.6 \pm 12.5$ & $78.8 \pm 15.5$ & $67.5 \pm 16.2$ \\
\hline Married & $198(82.5)$ & $58.8 \pm 17.0$ & $78.3 \pm 14.1$ & $68.7 \pm 15.9$ \\
\hline \multirow[t]{2}{*}{ Separated } & $18(7.5)$ & $65.7 \pm 20.4$ & $83.0 \pm 12.1$ & $73.6 \pm 13.2$ \\
\hline & & $\mathrm{F}=1.50, \mathrm{df}=2, p=.225$ & $\chi_{\mathrm{KWT}}^{2}=2.115, \mathrm{df}=2, p=.347$ & $\chi_{\mathrm{KWT}}^{2}=1.22, \mathrm{df}=2, p=.543$ \\
\hline \multicolumn{5}{|l|}{ Diagnosis } \\
\hline Breast $\mathrm{Ca}$ & $109(45.4)$ & $59.2 \pm 16.5$ & $79.7 \pm 12.3$ & $70.6 \pm 14.9$ \\
\hline Colon/Gastric $\mathrm{Ca}$ & $35(14.6)$ & $55.9 \pm 19.1$ & $71.0 \pm 15.8$ & $59.6 \pm 17.8$ \\
\hline Prostate/Testicular $\mathrm{Ca}$ & $12(5.0)$ & $56.3 \pm 18.8$ & $75.0 \pm 20.9$ & $62.9 \pm 13.2$ \\
\hline Lymphoma & $28(11.7)$ & $63.9 \pm 16.9$ & $82.1 \pm 11.3$ & $74.5 \pm 12.3$ \\
\hline Lung & $18(7.5)$ & $59.3 \pm 16.1$ & $86.3 \pm 8.9$ & $70.8 \pm 16.3$ \\
\hline \multirow[t]{2}{*}{ Others } & $38(15.8)$ & $59.6 \pm 16.3$ & $77.8 \pm 16.1$ & $69.7 \pm 16.1$ \\
\hline & & $\mathrm{F}=0.77, \mathrm{df}=5, p=.567$ & $\chi_{\mathrm{KWT}}^{2}=14.84, \mathrm{df}=4, p=.005^{*}$ & $\chi_{\mathrm{KWT}}^{2}=15.10, \mathrm{df}=4, p=.004^{*}$ \\
\hline \multicolumn{5}{|l|}{ Duration of disease } \\
\hline$<1$ year & $120(50.0)$ & $58.8 \pm 17.9$ & $78.8 \pm 13.7$ & $68.2 \pm 15.7$ \\
\hline $1-3$ years & $67(27.9)$ & $57.5 \pm 15.9$ & $80.3 \pm 13.5$ & $72.0 \pm 16.4$ \\
\hline \multirow[t]{2}{*}{$>3$ years } & $53(22.1)$ & $62.4 \pm 15.6$ & $76.6 \pm 15.8$ & $66.8 \pm 14.8$ \\
\hline & & $\mathrm{F}=1.353, \mathrm{df}=2, p=.26$ & $\chi_{\mathrm{KWT}}^{2}=2.038, \mathrm{df}=2, p=.361$ & $\chi_{\mathrm{KWT}}^{2}=3.332, \mathrm{df}=2, p=.189$ \\
\hline \multicolumn{5}{|l|}{ Type of treatment } \\
\hline Chemotherapy & $84(35.0)$ & $56.1 \pm 15.0$ & $80.8 \pm 13.4$ & $69.9 \pm 14.2$ \\
\hline \multirow[t]{2}{*}{ Concurrent therapy } & $156(65.0)$ & $60.9 \pm 17.7$ & $77.6 \pm 14.4$ & $68.4 \pm 16.6$ \\
\hline & & $t=-2.126, p=.035^{*}$ & $\mathrm{z}=-1.734, p=.083$ & $z=-0.494, p=.621$ \\
\hline
\end{tabular}

Note. n: Frequency, \%: percentage, $t$ : Student $t$-test, $p$ : $P$-value, F: One way ANOVA, $* p \leq .05$.

\section{Discussion}

Clinical nurse coordinators play a pivotal role in linking the efforts of various health disciplines to deliver a patientcentered quality service. ${ }^{[15]}$ The overall PMS of knowledge, perception and attitude in this study was 59\%,79\%, and 69\% respectively. A low level of knowledge indicates that cancer patients had a confusion regarding the roles of CNCs with the roles of other health disciplines such as nurses or physicians. The attitude of patients was significantly reliant on their perception towards nurse coordinators. Patients' perception of CNCs was significantly linked to their knowledge of coordinators' roles and responsibilities. Studies have proven that attitude revolves around awareness, i.e. knowledge and perception in a direct relationship. ${ }^{[16,17]}$ A study stated that the patients' perception can be influenced by their pre-service expectations of the service provider ${ }^{[18]}$ that is the patients' actual knowledge of the roles and responsibilities of CNCs in this study. Another study reported that patients' perceptions of disease risks and development influenced their attitude towards treatment preferences ${ }^{[19]}$ and that an effective communication about prognosis is a prerequisite to define goals of care, making treatment decisions, and planning for the 
future. ${ }^{[20]}$ This clearly indicates how nourishing the knowl- influence their attitude to communicate such needs to CNCs. edge of cancer patients and enhancing their perception can

Table 5. Factors significantly associated with higher perception and positive attitude $(\mathrm{n}=240)$

\begin{tabular}{|c|c|c|c|c|c|c|c|}
\hline & \multicolumn{3}{|c|}{$\begin{array}{l}\text { Perception } \\
\text { (Percentage mean score) }\end{array}$} & & \multicolumn{3}{|c|}{$\begin{array}{l}\text { Attitude } \\
\text { (Percentage mean score) }\end{array}$} \\
\hline & B(SE) & $t$ & $p$-value & & B(SE) & $t$ & $p$-value \\
\hline $\begin{array}{l}\text { Sex } \\
\text { (Male vs. female) }\end{array}$ & $-2.518(2.06)$ & -1.22 & .223 & $\begin{array}{l}\text { Sex } \\
\text { (Male vs. female) }\end{array}$ & $-3.77(1.77)$ & -2.13 & $.034^{*}$ \\
\hline $\begin{array}{l}\text { Age } \\
\text { (years) }\end{array}$ & $0.06(0.07)$ & 0.89 & .369 & $\begin{array}{l}\text { Age } \\
\text { (years) }\end{array}$ & $-0.09(0.06)$ & -1.47 & .144 \\
\hline $\begin{array}{l}\text { Education level } \\
\text { (University vs. School) }\end{array}$ & $0.05(1.86)$ & 0.027 & .978 & $\begin{array}{l}\text { Education level } \\
\text { (University vs. School) }\end{array}$ & $-0.67(1.59)$ & -0.42 & .675 \\
\hline $\begin{array}{l}\text { Marital Status } \\
\text { (Married vs. single) }\end{array}$ & $-1.60(2.47)$ & -0.65 & .518 & $\begin{array}{l}\text { Marital Status } \\
\text { (Married vs. single) }\end{array}$ & $0.93(2.11)$ & 0.44 & .662 \\
\hline $\begin{array}{l}\text { Duration of disease } \\
\text { (> } 1 \text { year vs. } \leq 1 \text { year })\end{array}$ & $0.25(1.85)$ & 0.13 & .893 & $\begin{array}{l}\text { Duration of disease } \\
\text { (>1 year vs. } \leq 1 \text { year) }\end{array}$ & $1.25(1.58)$ & 0.79 & .430 \\
\hline $\begin{array}{l}\text { Treatment } \\
\text { (Concurrent therapy vs. } \\
\text { chemotherapy) }\end{array}$ & $-3.91(1.98)$ & -1.98 & $.049^{*}$ & $\begin{array}{l}\text { Treatment } \\
\text { (Combination therapy } \\
\text { vs. chemotherapy) }\end{array}$ & $0.49(1.69)$ & 0.29 & .771 \\
\hline $\begin{array}{l}\text { Knowledge } \\
\text { (Percentage mean score) }\end{array}$ & $0.13(0.05)$ & 2.36 & $.019^{*}$ & $\begin{array}{l}\text { Perception } \\
\text { (Percentage mean score) }\end{array}$ & $0.72(0.06)$ & 12.92 & $<.001^{*}$ \\
\hline Constant & $72.548(5.06)$ & 14.35 & $<.001 *$ & constant & $16.39(5.60)$ & 2.93 & $.004 *$ \\
\hline
\end{tabular}

Note. B (SE): Beta (Standard Error), $t$ : Student $t$-test, $p$-value: Adjusted $p$-value, ${ }^{*} p \leq .05$.

Cancer treatments are stressful and their clinical pathway is filled with complications, such as opportunistic infections and medication side effects. ${ }^{[21]}$ Cancer patients on concurrent therapy revealed higher knowledge scores of the roles of CNCs compared to those on chemotherapy alone, yet the chemotherapy group had significantly higher perception in this study. Patients on concurrent therapy undergo more diagnostic tests and treatment modalities, all requiring higher coordination from CNCs. Therefore, their level of knowledge was related to their level of exposure to CNCs. On the same hand, the female sex factor was also a significant factor for higher attitude scores towards seeking help from CNCs which was comparable with findings in literature that highlighted a significant association between females and positive help-seeking attitudes. ${ }^{[22]}$ Patients suffering from lung cancer had the highest perception scores towards the $\mathrm{CNC}$ roles and responsibilities compared to other cancer categories. Furthermore, lymphoma cancer patients reported the highest attitude scores towards seeking the services of CNCs. Studies showed that lymphomas are more prevalent in younger age groups ${ }^{[23,24]}$ who might be more enthusiastic in battling cancer, more committed to treatment and more inquisitive about disease prognosis/clinical updates.

Anxious patients and their families can only find a wellcoordinated health care plan if they communicate their wor-

Published by Sciedu Press ries and express their needs to $\mathrm{CNCs}^{\left[{ }^{[25]}\right.}$ A clinical nurse coordinator delivering a comprehensive education to cancer patients undergoing various treatment modalities ensures higher compliance with the recommended medical and nursing instructions. ${ }^{[26]}$ The involvement of CNCs might reduce patients' anxiety, boost their adherence, and education on how to effectively manage the complications. In other words, the CNC could help in keeping the patient on the correct medical and nursing treatment protocols, such as simple infection prevention and control guidance. Therefore, it is of importance for any cancer patient to identify themselves with CNCs and seek their services during their hospital stay and visits.

\section{Conclusions}

Overall, the level of awareness and attitude towards clinical care coordinators among cancer patients was average. These coordinators play a pivotal role in delivering a wellcoordinated, high quality and safe health care service to cancer patients. Cancer centers should be aware that patients' knowledge about the roles and responsibilities of nurse coordinators is associated with a better patients' perception towards coordinators, which in return is associated with a more positive attitude towards seeking their services. Special consideration should be paid for patients on concurrent therapies who were more likely to have poorer perception 
towards clinical care coordinators compared to patients on chemotherapy. In addition, coordinators are expected to observe a more negative attitude towards seeking their services among male cancer patients.

\subsection{Limitations}

The present study was conducted in one health care setting providing services to a patient population complaining of cancer, a disease with distinctive characteristics. This study did not assess the attitude and awareness of patients complaining of other non-cancer medical conditions. Therefore, the study results might not be generalizable to other health care settings providing $\mathrm{CNC}$ services to non-cancer patients. However, findings in this study can be compared to similar study settings providing services to cancer patients elsewhere. Due to the fact that all cancer patients were exposed to CNC services in this setting, this study lacked the comparative analytical approach with those who were never exposed to $\mathrm{CNC}$ services. CNCs are assigned to various hospital departments, so the data collection tools used in this study can be customized and utilized by future studies conducted among other patient populations. The small size of cancer diagnoses groups made it difficult to investigate their outcome measures. This study measured and analyzed a self-reported measure of cancer patients who are generally under stress when visiting the institution for follow-up or treatment. Authors suspected a minimal chance of recall bias in the reporting some disease characteristics. In addition, authors suspected patients might have experienced some influence bias. Therefore the team of data collectors reassured the study subjects that their participation is anonymous and voluntary.

\subsection{Recommendations}

All cancer centers are advised to evaluate the awareness and attitude of cancer patients towards the CNCs and their services on annual basis. This could serve as a performance indicator for CNCs, so that any misconception is readily identified and resolved to boost up patients' satisfaction. Furthermore, patient satisfaction surveys can be launched and announced as an outcome parameter. The data collection tool adopted in this study can be customized for non-cancer patient populations in settings that don't employ CNCs. Authors recommend that future studies test the outcome measures in a comparative group design (patients exposed to $\mathrm{CNC}$ sevrices versus patients not exposed to their services).

Clinical nurse coordinators are advised to rapidly introduce themselves to newly admitted patients, orienting them on their rights and informing them about the CNCs' roles and responsibilities. Careful attention should be paid for any language or cultural barrier as well as other holistic needs a patient might express. Communication and interaction is crucial between the patient and the CNC. CNCs should be readily accessible with their contact information provided upon admission. They shall not refrain from calling for multidisciplinary meetings where the patients and their families are invited to join so that any concerns or queries are clarified and resolved. Last but not least, all health care workers are recommended to acknowledge the efforts offered by CNCs and perceive them as catalysts for an ideal patient-centered care.

\section{ACKNOWLEDGEMENTS}

This study was initiated by King Hussein Research Center, Amman, Jordan. The authors would like to thank the Research office at King Hussein Cancer Center for their support. Special thanks to the Chief Nursing Officer Dr. Majeda A. AL-Ruzzieh for her tremendous support and whose efforts made this project a success. Authors would like to appreciate the efforts of Mrs. Lara Afesh in language editing the paper.

\section{CONFlicts OF InTEREST Disclosure}

The authors declare that there is no conflict of interest.

\section{REFERENCES}

[1] Gardner G, Chang AM, Duffield C, et al. Delineating the practice profile of advanced practice nursing: a cross-sectional survey using the modified strong model of advanced practice. Journal of Advanced Nursing. 2013 Sep 1; 69(9): 1931-42. PMid:23186155 https://doi.org/10.1111/jan.12054

[2] Bryant-Lukosius D, DiCenso A, Browne G, et al. Advanced practice nursing roles: development, implementation and evaluation. Journal of Advanced Nursing. 2004; 48(5): 519-29. PMid:15533090 https://doi.org/10.1111/j.1365-2648.2004.03234.x

[3] Blair KA, Jansen MP. Advanced practice nursing: Core concepts for professional role development: Springer Publishing Company; 2015.
[4] Association AN. The value of nursing care coordination: A white paper of the American Nurses Association. Acedido em; 2012.

[5] Adler NE, Page AE. Cancer care for the whole patient: Meeting psychosocial health needs: National Academies Press; 2008.

[6] Bevans M, Sternberg EM. Caregiving burden, stress, and health effects among family caregivers of adult cancer patients. JAMA. 2012; 307(4): 398-403. PMid:22274687 https://doi.org/10.1001/ jama. 2012. 29

[7] Gerber DE. Targeted therapies: a new generation of cancer treatments. Am Fam Physician. 2008; 77(3): 311-9. PMid:18297955

[8] Al-Qudimat MR, Day S, Odeh D, et al. Clinical nurse coordinators: a new generation of highly specialized oncology nursing in 
Jordan. Journal of Pediatric Hematology/Oncology. 2009; 31(1): 3841. PMid:19125085 https://doi.org/10.1097/MPH.0b013e31 $818 \mathrm{~b} 3536$

[9] Radwin LE, Farquhar SL, Knowles MN, et al. Cancer patients' descriptions of their nursing care. Journal of Advanced Nursing. 2005; 50(2): 162-9. PMid:15788080 https://doi.org/10.1111/j.13 $65-2648.2005 .03375 \cdot x$

[10] Radwin LE. Cancer Patients' Demographic Characteristics and Ratings of Patient-Centered Nursing Care. Journal of Nursing Scholarship. 2003; 35(4): 365-70. PMid:14735680 https ://doi .org/10 $.1111 / j .1547-5069.2003 .00365 . x$

[11] Radwin L. Oncology patients' perceptions of quality nursing care. Research in Nursing \& health. 2000; 23(3): 17990. https: //doi.org/10.1002/1098-240X (200006) 23:3<17 $9:$ : AID-NUR2>3. 0. CO;2-T

[12] Bolton LB, Aydin CE, Donaldson N, et al. Nurse staffing and patient perceptions of nursing care. Journal of Nursing Administration. 2003; 33(11): 607-14. PMid:14608220 https://doi .org/10.1097/00 005110-200311000-00011

[13] Christopher KA, Hegedus K. Oncology patients' and oncology nurses' perceptions of nurse caring behaviours. European Journal of Oncology Nursing. 2000; 4(4): 196-204. PMid:12849014 https://doi.org/10.1054/ejon.2000.0108

[14] Irurita V. Factors affecting the quality of nursing care: the patient's perspective. International Journal of Nursing Practice. 1999;5(2):8694. PMid:10633634 https://doi.org/10.1046/j.1440-172x. $1999.00156 . \mathrm{x}$

[15] National Coalition on Care Coordination. Implementing Care Coordination in the Patient Protection and Affordable Care Act. 2010. Available from: http://www.nyam.org/social-worklea dership-institute/docs/publications/N3C-Implement ing-Care-Coordination.pdf

[16] AlAteeq M, Alrashoud AM, Khair M, et al. Smoking cessation advice: the self-reported attitudes and practice of primary health care physicians in a military community, central saudi Arabia. Patient Preference and Adherence. 2016; 10: 651. PMid:27175065

[17] Sabouhi F, Babaee S, Naji H, et al. Knowledge, awareness, attitudes and practice about hypertension in hypertensive patients referring to public health care centers in Khoor \& Biabanak 2009. Iran J Nurs Midwifery Res. 2011;16(1):35.

[18] Samina M, Qadri GJ, Tabish SA, et al. Patient's perception of nursing care at a large teaching hospital in India. International Journal of Health Sciences. 2010 Feb 19; 2(2).

[19] O'Brien MJ, Moran MR, Tang JW, et al. Patient Perceptions About Prediabetes and Preferences for Diabetes Prevention. The Diabetes Educator. 2016 Dec 1; 42(6): 667-77. PMid:27621093 https: //doi.org/10.1177/0145721716666678

[20] Robinson TM, Alexander SC, Hays M, et al. Patient-oncologist communication in advanced cancer: predictors of patient perception of prognosis. Supportive Care in Cancer. 2008 Sep 1; 16(9): 1049-57. PMid:18196288 https://doi.org/10.1007/s00520-007-037 2-2

[21] Rowland JH, Kent EE, Forsythe LP, et al. Cancer survivorship research in Europe and the United States: where have we been, where are we going, and what can we learn from each other? Cancer. 2013 Jun 1; 119(S11): 2094-108. PMid:23695922 https : //doi.org/10.1002/cncr. 28060

[22] Suk Kyung NAM, et al. A meta-analysis of gender differences in attitudes toward seeking professional psychological help. Journal of American College Health; 2010; 59(2): 110-116. PMid:20864437 https://doi.org/10.1080/07448481.2010.483714

[23] Horning SJ. Hodgkin's lymphoma. In: Abeloff MD, Armitage JO, Niederhuber JE, et al., eds. Clinical Oncology. 4th ed. Philadelphia, PA: Elsevier Churchill-Livingstone; 2008: chap 111. https : //doi.org/10.1016/b978-0-443-06694-8.50115-9

[24] National Cancer Institute: PDQ Childhood Hodgkin Lymphoma Treatment. Bethesda, MD: National Cancer Institute. Date last modified 10/25/2012. Available from: http://cancer.gov/cancertopics/pdq/treatment/ch ildhodgkins/HealthProfessional

[25] Dean M, Street RL. A 3-stage model of patient-centered communication for addressing cancer patients' emotional distress. Patient Education and Counseling. 2014 Feb 28; 94(2): 143-8. PMid:24169023 https://doi.org/10.1016/j.pec. 2013.09.025

[26] American College of Surgeons Commission on Cancer. Cancer Program Standards 2012: Ensuring Patient-centered Care. Version 1.2. 1. 2012. 